\title{
Tipping the balance back towards emancipation: Exploring the positions of Flemish community sport practitioners towards social control
}

Current debates highlight the dualistic nature of community sport, which is shaped by both emancipating logics and controlling logics. Critical scholars have warned against the current prioritisation of controlling logics over emancipating ones, as this might lead to instrumental approaches in which the vulnerability of young people is managed rather than tackled. However, little research has been conducted on the way in which practitioners perceive and act upon the dominance of social control as a value within community sport. In this article, we report on the findings of a qualitative study into three community sport initiatives in Flanders, Belgium. The data indicate there are small emancipatory moments within the daily practice of community sport. Based on these results, we propose a reconfiguration of the concept of emancipation from being a solid, utopian ideal towards being a search for moments where the dominant logics of social control are momentarily disrupted.

Keywords: community sport, social control, emancipation, transformation, resistance

\section{Introduction}

Community sport has always focused on providing an inclusive approach (Hylton and Totten 2008), particularly on establishing objectives (for example social cohesion), which have the potential of being emancipating levers to combat social exclusion. However, these emancipating objectives have been put under pressure due to the instalment of mechanisms of social control (Skinner 2008) directed at managing socially vulnerable young people, rather than tackling vulnerability in itself (Brown 2017; Harrison and Sander 2014; Rose 2000). Within the community sport field, scholars have warned the dominance of controlling logics above emancipating ones (Darnell 2010; Hartmann and Kwauk 2011; Spaaij 2013). In view of this, scholars have critiqued the pre-eminent position of neoliberal regulatory and controlling logics and the 
way in which their supremacy above emancipatory logics suppresses any consideration of contesting and breaking social order with the intention to achieve greater social justice and equality (Darnell 2010; Hartmann and Kwauk 2011; Spaaij 2013).

This article tackles the question of how practitioners position themselves in relation to dominant controlling logics within their practice. It is based on a study of the community sport practitioners' perspectives on the relationship between community sporting programmes and social cohesion in Flanders, Belgium. The article is comprised of five sections. The first gives insight into the double character of community sport, which comprises both emancipatory and controlling logics, and the way in which these logics relate to each other like uneven weights on a balance tipped by controlling logics. The first section also focusses on research gaps with regard to an institutional perspective of this imbalance. The second part defines the methodology of the qualitative research conducted for this study. The third section presents the results, while the fourth and fifth sections provide a discussion and conclusion, respectively.

\section{Community sport as a dichotomised practice}

\section{Community sport as a practice of emancipation}

In Western European society, community sport was brought to life following the observation that vulnerable young people were increasingly underrepresented in traditional sporting clubs, the labour market, and in education and social work (Crabbe 2007, 2009; Hylton and Totten 2008). This underrepresentation was indicative of the broad exclusion of these young people from the recourses, rights, goods, services and opportunities provided by society (Levitas et al. 2007). Community sport initiatives were installed and are currently maintained under the understanding that they can 1) provide a solution to social exclusion in the form of sporting participation by using an 
alternative and inclusive approach, and 2) oppugn the broader processes of exclusion within society. The inclusive approach suggests that community sport should be part of the leisure time of vulnerable young people on the basis of five attributes: (1) working from a demand and needs driven perspective, (2) collaborating with actors in the fields of sport, welfare, youth and community, (3) using diverse organizational formats, (4) promoting a wider notion of sport that exceeds a sport technical understanding of it and (5) using infrastructural facilities (Hylton and Totten 2008; Theeboom et al. 2010).

With regard to the ability of community sport to combat broad societal exclusion, the literature often refers to the transformative potential of community sport (Hartmann and Kwauk 2011) or, more precisely, its ability to move beyond providing merely individual benefits to creating progressive social and cultural change (Spaaij, Oxford and Jeanes 2016; Wright 2016). Creating wider social benefits from a transformative perspective implies striving towards the establishment of social justice and equity by questioning, challenging and combatting the current social order and the political and social conditions that determine inequality (Darnell 2010; Hartmann and Kwauk 2011; Spaaij 2013).

Research on this transformative potential has been conducted in into the broader sportfor-development field, particularly on the basis of two theoretical frameworks: that of Freire's critical pedagogy $(1998,2005)$ and the capability approach (Sen 1999; Nusbaum 2011; see, for example, Darnell and Dao 2017; Nols et al. 2018; Spaaij, Oxford and Jeanes 2016; Suzuki 2017; Wright 2016). Research which focuses on the framework of critical pedagogy employs Freirean key concepts such as critical reflection, praxis, problem posing, dialogue and transformative learning to analyse community sporting programmes. In particular, the framework of Freire provides a way to further acknowledge and invigorate belief in the empowerment-based pedagogy of 
community sport, wherein the emancipation of vulnerable young people is key (Wright 2016). Scholars have described this emancipatory character of community sport as an activist dimension as it triggers young people to 'transform their realities through education, research, reflection and action' (Luguetti et al. 2016, 331). Community sport practitioners are believed to give form to this activist dimension by steering participants towards critically seeing 'what is' and by letting them imagine and act upon 'what might be', namely, a more equal reality (Luguetti et al. 2016, 345). Crabbe (2007 38), for example refers to an '[...] alternative means of organising and realising the potential of socially marginalised young people by engaging in a similar orientation towards agitation and action'. This Freirean perspective is closely linked to broader emancipatory approaches as those within the radical youth work movement, described by Belton $(2010,69)$ as ' $[\ldots]$ informed by political and moral values: opposition to capitalism and authoritarianism, belief in equality and respect for the environment [...]'.

With regard to Sen's capability approach, scholars (see, for example, Suzuki 2017; Svensson and Levine 2017) have employed this framework as a way of seeing the people-centred processes that enhance the capabilities of vulnerable groups (for example knowledge) within sport-for-development programmes. Research on this is based on Sen's theory $(1992,1999)$, which states that capabilities represent freedom or the extent to which people can choose from an arsenal of possibilities, and that social exclusion is a form of capability deprivation. Furthermore, the capability approach investigates the determination of structure (social structures) and agency (ability of individuals to exercise freedom) on these capabilities (Suzuki 2017). Scholars such as Darnell and Dao (2017) take Nussbaum's (2011) theory as a starting point of research, in which capabilities are perceived as the abilities residing within a person (internal 
capabilities) as well as the opportunities which stem from the combination of personal, political, social and environmental opportunities (combined capabilities).

Both the critical pedagogy framework and the capability approach have been used within the sport-for-development literature to analyse the transformative potential of these programmes, such as those found in community sporting programmes with a focus on their pedagogies and educational philosophies (Nols et al. 2018).

\section{Community sport as a practice of control}

Notwithstanding the emancipating character of community sport, the belief that it should be a practice of transformation has been put under pressure by processes of privatisation, marketisation and consumerisation. Under influence of neoliberal policy, regulatory and controlling logics have become pivotal with regard to the organisation of the welfare state in general (Brown 2017; Harrison and Sander 2014; Rose 2000). Although the concept of neoliberalism is a contested one, there seems to be consensus amongst scholars that neoliberalism is a political project steered by deregulation, privatization and the withdrawal of the state (Harvey, 2005; Wacquant, 2012). Wacquant (2012), for example, defined neoliberalism as a project that exceeds a mere economic regime, in which the state is mobilised not only to 'safeguard financial institutions', but simultaneously to 'repress popular resistance to the neoliberal drive [...]' (Wacquant, 2012, 69) by disciplining welfare recipients and 'turning social support into a vector of discipline' $(2012,72)$. This mobilisation of the welfare state implies that values such as conditionality, responsibility and contracting (Brown 2017; Rose 2000) are key to the way in which 'advanced' liberal democracies and citizens stand in relationship to each other (Rose 2000). The withdrawal of the state suggests the decreased support of governments towards the effectuation of collective goals such as social justice and equality (Piessens 2008). The decreased support of governments is 
furthermore accompanied by the redirection of that responsibility towards non-state actors (Kelly 2012). Community sport is seen as an expedient setting in which to take up that responsibility as it reaches a group that embodies two characteristics, of particular interest to neoliberal welfare states: the vulnerable and the young.

In her work, Brown (2017) claims that liberal democracies aspire to manage the phenomenon of vulnerability through the development of technical solutions. The focus on vulnerable young people in particular derives from a pre-emptive approach (Crawford 2009), which is based on the idea that they are not mature enough and therefore unable to combat negative influences that might disrupt their development as responsible citizens (Brown 2014). As a result, interventions should 'forestall the potential escalation of bad behaviour on both the individual and community level' (Crawford 2009, 3).

Therefore, community sport initiatives in particular are praised by local policymakers for their "presumed capacity to "reach" and "manage" a constituency of the "excluded" who have proven increasingly troublesome for more traditional interventionist agencies' (Crabbe 2007, 39). In the practice of community sport, the preemptive approach referred to by Crawford (2009) is effectuated in the 'potential-threat' discourse (Kelly 2010, 129), in which vulnerable young people are perceived as threats to the social order and, at the same time, as potential workers of the future. Community sport acts upon this by adopting an approach towards the 'community governance of youth' (Kelly 2012, 1) that tackles the anti-social behaviour of young people on the one hand and redirects them to employment, education and training on the other hand (Kelly 2010). The adoption of regulatory strategies within community sport stems from the conviction that young people should be able to lead successful lives as free, rational, resilient and self-reliant citizens (Brown 2017; Harrison and Sanders 2014) and 
furthermore, that community sport has the ability to 'shape the individual as a social subject' (Ekholm 2017, 2).

\section{Between emancipation and control: An unbalanced scale}

In her research, for example, Kelly (2012) highlights the way in which sport-fordevelopment programmes contribute to both the development and the regulation of young people. As such, community sport can be perceived as a dichotomised practice, comprising both emancipating and controlling logics.

Although the practice of community sport has been celebrated for its potential to 'build the moral and social capacity of individuals residing in a local community' (Harrison and Sanders 2014, 87), some scholars claim that this does not come without pitfalls (see, for example, Darnell 2010; Hartmann and Kwauk 2011; Spaaij 2013). Skinner et al. (2008) have argued that the 'traditional delivery of sport development programmes, especially at the community level, faces particular challenges under neoliberal ideology' (Skinner et al. 2008, 254). The adoption of social control might stand in a tense relationship with emancipation objectives (Skinner et al. 2008) as an emancipation perspective suggests contesting of the social order and structural barriers which hinder the enhancement of social justice and equality (Darnell 2010; Hartmann and Kwauk 2011; Spaaij 2013) whereas the controlling perspective advocates 'reproducing and reinforcing the social status quo' (Hartmann and Kwauk 2011, 292).

Scholars have identified the relationship between these logics as tense, as if they stand in constant conflict like two weights on opposite ends of a scale. This tense dichotomised relationship has been drawn upon from several perspectives. Kelly (2012) for example refers to social control versus social development while Black (2017) discusses this issue as a matter of top-down control versus bottom-up emancipation. Nols et al. (2018) refer to an instrumental versus politicised approach while Darnell and 
Dao (2017) refer to dominant versus transformative logics. According to scholars, this tense relationship is due to the fact that the controlling logic tends to override the emancipating one, leaving the balance between emancipation and control uneven. In particular, scholars have critiqued the way in which the dominance of controlling logics paves the way for a solely technical or 'instrumental approach' (Crabbe 2009, 117) in which participants are assumed to lead successful lives by means of self-improvement, self-management and self-determination (Darnell 2010; Ekholm 2015; Hartmann and Kwauk 2011). Whereas creating responsible citizens seems positive by definition, the belief that one should be able to do so, despite structural barriers in society (Brown 2017), is what is perceived as a dangerous reasoning as it tends to completely restrain emancipatory logics within community sport. Thus, on this balance between reinforcing power structures and challenging them (Wright 2016), the controlling logic seems to tip the scale and moreover seems to totally eradicate the counterweight of the emancipating logic.

\section{Shifting the research perspective on practitioners: From educators to social policy actors}

Research on the double character of sport-based interventions, such as community sport, is particularly focused on the educational dimensions of such programmes. As we described above, the emancipating character of community sport is mainly researched through theoretical frameworks such as those found in critical pedagogy and the capability approach, in which attention is paid the role of community sport practitioners as educators.

However, the sport-for-development literature has claimed that it is important to pay attention to this topic from a policy perspective (Black 2017, 18). In particular, Black argues for the importance of investigating the relationships between practitioners 
and 'top down organisations' such as the state (Black 2017, 18). On the relationship between community sport and the government, Spaaij (2009) suggests that whereas sport-based interventions create the illusion of providing a non-state intervention, they are merely the tentacles of a top-down community governance strategy (Spaaij 2009). Blackshaw and Crabbe $(2004,82)$ describe this as follows: 'Rather than being emancipatory the welfare services today constitute a second-rate and repressive regime, which have recourse to the expert and governmental "gaze" of those employed by the state: the DSS officer [Diplomatic Security Service], the community sport development worker, the GP [General Practitioner], the social worker, the probation officer, and so forth that collectively "police" the "flawed consumer".' Then again, Kelly (2012) states there is a need for a more nuanced analysis on the idea of sport-based interventions as 'governing at a distance'. In essence, Kelly (2012), amongst others, perceives practitioners as more than only educators. Rather, she acknowledges that practitioners can 'act as advocates and mediators with the potential to influence policy and practice' $(2012,18)$ and thus can be perceived as social policy actors. She urges this as a necessary research perspective to understand controlling logics. However, this kind of research has received little attention in the international sport-based intervention literature (Kelly 2012).

Therefore, this article does not start from a research perspective with regard to practitioners as solely educators, neither is it our objective to conduct a policy analysis of community sport. Rather, it is our aim to shed light upon the ways in which community sport practitioners as social policy actors deal with controlling logics. Herein, we align with the research of De Corte and Roose (2018), who conducted research from a social policy perspective through acknowledging non-profit 
practitioners as social policy actors within an open-ended and democratic practice, pointed at the reconfiguration of social order.

\section{Methodology}

\section{Research context}

For this article, we obtained data from a qualitative study ${ }^{1}$ on the relationship between community sport and social cohesion, which was conducted within three community sport initiatives in Flanders (the Dutch-speaking part of Belgium). These three initiatives were located in the cities of Bruges, Kortrijk and Ronse, and were supervised by three separate and diverse organisations.

Bruges and Kortrijk are both regional cities with population sizes of 117,613 and 75,506 (Flemish Government A, B). In Bruges, community sport is embedded into the Public Centre for Social Welfare (OCMW), the main public municipal institution in Belgium that oversees social services in order to warrant the right to social assistance and integration. Community sport in Bruges was established in 2009 as one of nine community sport trial projects in Flemish regional cities. Community sport provides open-air activities within six neighbourhoods as well as a sport lecture series, school sport and sport events. They primarily focus on young children and teenagers from vulnerable areas as well as young asylum seekers. (Community Sport Brugge 2016). In Kortrijk, community sport is placed among several initiatives for vulnerable youngsters in the youth and welfare sector. The practice was established in 2006; however, in 2014, it merged with five other municipal youth and welfare organisations, resulting in a non-profit organisation named AJKO (Active Youth in Kortrijk). The activities are quite similar to those provided by Community Sport Bruges, except for the fact that Community Sport Kortrijk provides neighbourhood sport in five vulnerable 
quarters in Kortrijk and focuses on children (under to the age of 15) in particular and, to a lesser extent, on young teenagers. (Community Sport Kortrijk 2016). Ronse is a municipality with a population of 25,925 (Flemish Government, C). In Ronse, community sport was established in 2002. The local government takes on the organisation of community sports as it is part of regular sporting provisions.

Community sport also provides neighbourhood sport in three vulnerable areas, although to a lesser extent than Community Sport Kortrijk and Bruges, as the focus is rather on sport lecture series and the training of community sport volunteers as part of the Street Action Project (Municipality Ronse 2008-2013). All three practices base their choice of target group and neighbourhood on demographic statistics, especially in regard to the poverty rate, which is based on demography, accommodation, education, and unemployment. Neighbourhoods described as 'vulnerable' are characterised by high numbers of single-parent families, children in special education, unstable accommodation and low employability (Province West-Flanders 2014).

\section{Data collection}

The three initiatives where selected on the basis of two criteria: (1) their mission, vision and goal-setting in terms of social cohesion and (2) the diversity that the bring to the selection of initiatives in terms of the size of the city, the size of the setting, the organisational structure, geographical spread and target group. Eighteen community sport initiatives showed interest in the research project, three of those eighteen were selected.

In 2016, the first author of this article conducted 34 semi-structured interviews with practitioners, partners, and key figures (financial stakeholders and ex-practitioners) across the three initiatives. 16 practitioners, 17 local partners and one ex-practitioner were selected across the three practices through a purposive sampling method (DiCicco- 
Bloom and Crabtree 2006) in order to enhance the richness of the data. In this, their experience within the context of community sport was used as the main criterion. Of the 34 respondents, 20 had between one and ten years of professional experience in community sport or a related sector (youth, welfare, community, sport). Ten respondents had between 11 and 20 years of working experience. There was no information regarding the working experience of four of the partners.

The objective of the interviews was to shed light upon the way in which community sport practitioners in Flanders conceptualise social cohesion, on the one hand, and how they see their practices contributing towards social cohesion, on the other hand. The interviews were guided by four main questions: (1) What are you seeking to achieve when taking social cohesion as an objective of community sport? 2I) What are the expected effects of the establishment of social cohesion and why is it important work towards achieving them? (3) How and to what extent does community sport currently contribute to social cohesion? And, (4) which mechanisms and conditions influence this contribution to social cohesion?

\section{Data analysis}

All interviews were audiotaped and transcribed verbatim and then thematically analysed with the help of NVivo11 (Dicicco-Bloom and Crabtree 2006; Mortelmans 2007). We applied a conventional content analysis (Hsieh and Shannon 2005) to analyse the transcripts.

The coding itself was largely inductive rather than deductive as we allowed the themes to arise from the data using a coding tree (Hsieh and Shannon 2005). The coding tree allowed us to organize the data into a hierarchical structure, existing of categories, for example social cohesion, subcategories, for example equality and themes, for example social control (Hsieh and Shannon 2005). Throughout the data analysis, we 
obtained insight into the complex character of social cohesion as a social objective, making social cohesion the main category in our coding tree. Whereas we discussed the general conceptualisation of social cohesion by practitioners in a previous paper, for the purposes of this paper, we focused on the specific subcategories and themes that gave us insight into the way in which practitioners position themselves towards the dominance of controlling logics within community sport. This resulted in the selection of the following themes (1) social control, (2) prevention, (3) repression, (4) nuisance, (5) delinquency, (6) procedures and (7) legitimation.

For the analysis, clusters were formed on the basis of the relationships between the above standing themes in order to report on the data. (Hsieh and Shannon 2005, Westbrook 1994). Furthermore, fifteen percent of the transcripts were analysed by the two other authors of this article in order to verify the credibility of the data analysis and interpretation. The ethics commission of the respective university (project 2016/32) formally approved this study.

\section{Findings}

This section is structured around three findings that emerged from the data in relation to participants' experiences of pressure towards their practice. The first finding draws upon that pressure, in particular with regard to what practitioners refer to as the 'marketisation of community sport'. The second and third findings give insight into two tensions derived from that pressure and the way in which practitioners act upon that pressure. Each finding is discussed with quotations from the interviews to illustrate them.

\section{The marketisation of community sport}

During the interviews, practitioners clearly gave us insight into the increased amount of 
pressure to exert social control as part of their task as community sport practitioners. Practitioners gave notice to the fact that this pressure is clearly steered by a neoliberal shift, in particular when it comes to the marketisation of community sport. One respondent in particular used the example of 'tendering' as a way to give insight into this shift.
In recent years, a marketisation of youth work has occurred wherein you have to work with a tender, which means that a job is written out for every organization in the field to sign into. Often, the critical factors to decide who gets the job are pinpointed on who has the cheapest price. So the decision is $60 \%$ dependent on the price and $40 \%$ on the content. [...] Moreover, what I notice is that local governments want results right away (I1).

This shift suggests that community sport services are expected to compete with one another to obtain funding from local governments. Practitioners consider these sources of funding, in which the amount of funding is conditional to the output of practices, to be a poisoned gift. One respondent stated:

We need to reach out to a certain number of vulnerable young people to get our funding. We are currently just merely above that number, so therefore we receive money. However, if we do a really good job with that funding [by getting youngsters out of their vulnerable situations], we risk falling short on the number of reached youngsters. So, by doing a good job, we are left without funding. (I4)

Respondents referred to this way of funding as contradictory. Instead of being stimulated, practitioners are demotivated to make the situations of youngsters less vulnerable. To do so would mean a decline in the amount of vulnerable youngsters practitioners reach and thus would imply a decline in the funding they receive. Furthermore, in addition to reaching a certain amount of young people, policy makers have high expectations that community sport practitioners will avert criminal behaviour, as reported in state-of-the-art literature (see, for example, Kelly 2012). In order to 'sell' 
their programme to policy makers, practitioners therefore often highlight the output they achieve on the margin of their core business.

If I would have to convince a policy maker of the effectiveness of community sport, I would stress that community sport keeps socially vulnerable young people away from the streets, from exercising criminal activities, from exercising vandalism. I think, in a sense, we do such things although it is not the core of our practice (I2).

According to practitioners, the question of policy makers is based on the specific on the construction of problems regarding to nuisance behaviour and its externalisations: a large number of children playing in a small area, lollygagging, claiming public space and (in extreme cases) criminal behaviour. One respondent argues:

We receive a huge amount of complaints on nuisance. Moreover, these complaints are formulated with the expectation that community sport can control these issues (I28).

Thus, practitioners stated that these questions led to the expectation that community sport practitioners become the (new) 'neighbourhood supervisors' (I6). Among the participants' answers, there was consensus that there is increasing pressure to implement social control and develop community sport as a preventive and repressive force. In what follows, we will pinpoint the tensions between these ideals of policymakers and the values of community sport that we retrieved from the data. Moreover, we go further into how practitioners deal with these tensions.

\section{Tension 1: Prevention and repression, no two birds of a feather}

As we mentioned above, scholars have argued how community sport has become subject to regulatory and controlling logics in which conditionality, responsibility and contracting are key (Brown, 2017; Rose, 2000), as part of a broader neoliberal project. 
Practitioners acknowledge this neoliberal pressure within the mobilisation of community sport as both a preventive as well as a repressive force. However, practitioners make a very clear distinction between prevention and repression and the way in which they position themselves towards this. Practitioners agree on the fact that community sport has a preventive potential. This potential has furthermore been maximised in recent years by shifting attention from young adolescents towards children. One respondent states:

Adolescents already have their own piece of mind. However, by steering young children, we can work preventively and make sure they do not end up any worse than their current behaviour suggests (I9).

Thus, certain behaviour which is believed to have the potential to spiral out of control and become criminal behaviour is then tackled from the start: "when they get bored, they do all sorts of things and before you know it, they run into the police' (I18). Moreover, within this preventive logic, practitioners make linkages between the way in which they can steer children's behaviour and the way in which their behaviour is steered by their parents. So, practitioners not only attempt to intervene in the leisure time of children but moreover control the way in which parents educate their children by teaming up with services which are specialised in solving parental questions on education.

Moreover, practitioners stress that this preventive logic also implies that they try to reach youngsters who have lost all links with institutional life. Hence, practitioners focus their attention on young people who have 'disappeared from the radar' (I1) of institutional services. One respondent notes:

We are confronted with young people who no longer attend school. They hang around in the streets all day. Some of them stay home all day. And then we ask 
ourselves, 'where are they?' and moreover 'how do we reach them?'. Moreover, because they no longer attend school, school can't signal us when they aren't attending classes and thus they become invisible (I1).

Thus, practitioners express that the 'missing' links between young vulnerable adolescents and institutions not only causes them to 'disappear from the radar', but also makes it harder for community sport to be allocated to them. Thus, practitioners attempt to get young people 'back on the radar' of institutional services, for example, in order to get them off the streets, as the above excerpt suggests. They express that they do so by redirecting young people from community sport to regular amenities such as regular sports, and also school, the labour market and social work.

Practitioners expressed how policy makers are praising community sport for its preventive potential: 'for policy-makers, redirecting and reconnecting vulnerable young people to mainstream society is the precedency of community sport' (I1). However, they further elaborate on the fact that policy makers often exercise a hidden agenda that aims to shift this preventive logic to a repressive one. Practitioners experienced a clear tension between prevention and repression. They explained that they do not condemn prevention (of criminal behaviour) per se, as they accept it as a vulnerable function within community sport. However, they very strongly believe that repressive forms of social control should not be exercised through community sport.

I think disciplining young people is a good thing per definition. However, I do think it is not community sport that has to discipline them. Community sport should be about having fun, relaxing and coming in whenever you feel like it (I11).

Rather, they stress that their way of dealing with social control is one which creates opportunities by giving alternative approaches, rather than limiting opportunities, which appoints a rather emancipating logic. 
Community sport in general should not be the buffer against nuisance. We are no police officers; instead we try to work with these young people, not against them (I7).

Along these lines, they believe that by offering something in the neighbourhood that could deter young people from deviant behaviour, there is no need to execute a repressive form of social control. Within this alternative approach, practitioners take unconditionality as a basic principle of their practice: 'everywhere young people are confronted with conditions and stipulations, maybe there is need for a space in which nothing needs to happen' (I29). Remarkably, practitioners adopt unconditionality as a basic starting point, although they express that this is challenging as they are often tempted to fall for the offer of using repressive forms of social control, as it would provide them with a more official mandate to demand certain stipulations from young people. One respondent explains the difference between community sport and repressive institutions as follows.

The big difference between them and us is that we often collide with these moments of incompetence, we can appoint the problem as such. [...] However, besides identifying the problem, there is nothing we can do (I7).

Notwithstanding this affront, practitioners set up an unconditional approach as a countermovement against the conditionality that can be found in these repressive institutions, as they want to avoid emulating the conditionality of the regular facilities that have failed to provide positive experiences for these youngsters in the past.

Some of the young people are disappointed when they are obliged to do certain things. Then, they compare community sport with for example school (I1).

By not giving into this repressive way of working, practitioners aspire to protect the trustworthy relationship between themselves and the participants. 


\section{Tension 2: Standardisation versus customisation: A different reading of equality}

A second tension that we identified from the interviews with practitioners stems from a critique of the standardisation of output and the conditions of that output, as a result of neoliberal pressure. In particular, practitioners critique the fact that the instrumental approach, which social control suggests, provides a de-humanising way of looking at participants, as if they were just numbers on a sheet. Practitioners draw upon this critique from the observation that the lifeworld of participants and thus, their life conditions have little to no place in the discussions between policy makers and practitioners. Practitioners have particularly drawn upon this tension with regard to the way in which they are expected to report to local governments. For example:

Sometimes the perception of policy makers is so different from ours that they can't imagine the fact that projects can fail due to the circumstances in which participants life. When they say: 'just force them to come over here', it shows that they aren't so understanding (I1).

Thus, practitioners state that policy makers adopt an investment logic, which suggests that policy makers expect a clear-cut return on their financial investments in the form of more responsible participants. Thusly, practitioners notice a tendency towards what they call 'output financing' (I1) wherein the amount of financial input community sport receives is directly dependent on its output, often in the form of clear-cut numerical indicators. Moreover when programmes fail, participants are blamed for not taking up the opportunities they were provided with, and practitioners are accused for not making them do so. In the reasoning of policy makers, thus, equality involves giving all participants equal opportunities. Furthermore, this standardised approach suggests an idea that participants are passive beings who merely need to undergo whatever is needed to lead them towards becoming active and responsible citizens. 
As a reaction to this idea of equality, practitioners attempt to bring in an alternative, and according to them, 'human' perspective into discussions with policy makers. Participants do so by giving policy makers insight into the life conditions of participants, ideally through the stories and experiences of young people themselves:

\footnotetext{
We got together in a meeting with the alderman, and we gave one of our participants the chance to explain what community sport means to him and moreover, to explicate some bits and pieces of his situation at home. And by doing so, we opened the eyes of the alderman (I1).
}

In this fashion, practitioners stress the importance of considering the life conditions of vulnerable young people as a way to counterbalance the technical and instrumental approach. It concerns an approach in which equality is not only about a standardised arsenal of opportunities, but rather the customisation of those opportunities to the life circumstances of participants. Furthermore, this customisation of opportunities through the interventions of community sport can only happen with the 'active agency' of participants as an important precondition. One respondent argues:

We can trigger young people by asking them: 'should we do something with this?; 'should we help you with this?'. Then, it is their choice. And if they say: 'leave me alone, I'm perfectly happy in this situation', then we don't have the pretention to say: 'let's do something with this!'(I8)

\section{Discussion}

Within the field of sport-for-development studies, scholars have argued that the emancipatory character of community sport has been put under pressure due to the insertion of neoliberal- regulatory logics. Therefore, some scholars (Darnell 2010; Hartmann and Kwauk 2011) argue that the transformative potential of community sport should be investigated through questioning if they either challenge or rather reproduce inequality (Kelly 2012). In order to fully grasp this, we explored the institutional 
relationship between practitioners and local policy. To do so, we analysed data from a Flemish study on the perspectives of community sport practitioners on social cohesion. We focused on the question of how practitioners experience and deal with the preeminent position of controlling logics on an organisational level. With regard to the role of practitioners in this matter, it has been suggested that the challenges they face under pressure of neoliberal policy might be beyond their capacity to solve this (Crabbe 2007).

The results of this study partially confirm the existing body of literature, as we found that community sport practitioners clearly recognise and acknowledge the tension that neoliberal pressure gives them on a daily basis. They pinpointed the marketisation of community sport as a clear externalisation of this neoliberal pressure, for example, through tendering and output financing. Moreover, we drew upon two particular tensions they have experienced in their daily practice: (1) the tension between prevention and repression and (2) the tension between standardisation and customisation. Based on the data we retrieved, we disagree with the idea that the prioritization of controlling logics above emancipating ones is inescapable for participants, and that they are incompetent of dealing with this pressure. Whereas the work of Crabbe (2007), among others, suggests that these feelings of incompetence leave little place for strategies of resistance, the results of this research do show ways in which community sport practitioners have developed strategies of resistance.

Respondents recognised the reality in which they are committed to work, namely one in which the establishment of social control dominates the welfare agenda. However, practitioners looked for ways to invert controlling dynamics.

Practitioners avoided form repressive forms of social control by making a clear distinction between prevention and repression and by putting unconditionality upfront 
as a countermovement against the conditional approaches of repressive institutions. Furthermore, practitioners critiqued the way in which a controlling logic suggests striving towards equality from a standardised perspective (opportunities are equal for everyone so not taking them is an individual responsibility) and simultaneously try to bring in a notion of equality from a customized perspective (making the chances to take up those possibilities equal for everyone). Practitioners did so by respecting their participants as active agents and by inserting the social, financial, intellectual and emotional life conditions of participants into their communications with local policymakers.

The data do not reveal any great, explicit, alternative logics. Rather, they show traces of them, wrapped in small, momentary, pockets of emancipation. The way in which practitioners deal with dominant logics of control, could be perceived as a form of soft control, wherein practitioners are merely easing participants into repressive measures. However, researchers on the emancipatory potential of sport-based interventions have come to similar findings and plea for recognition of the relevance and importance of these small findings. For example, in their research Nols et al. (2018 12) state that '[i]t is important not to undervalue the modest evidence found in this study which can be considered as “micro-victories” (Leahy et al. 2017)'. Tomas and Davies (2005) have theorised these specific strategies as micro-politics of resistance or else as "small pockets of resistance", which follow from the everyday struggles and tensions of practitioners. Furthermore, Spaaij et al. (2016) gave insight into the way in which measurement of resistance and thus processes of "simultaneously "playing the game" and seeking to disrupt it' (Aronson and Smith 2014, 444), can in fact be perceived as indicators of success, however small they may be. 


\section{Conclusion}

The findings reported in this article have implications for both academic debates and the field of practice. In the discussion, we drew upon the small momentary pockets of emancipation which we retrieved from the data. On the basis of those findings, we argue for the importance of two research objectives.

First, we suggest a theoretical reconfiguration of the concept of emancipation. We suggest moving away from one big utopian narrative of emancipation (Thomas and Davies 2005), by letting go of the idea that emancipation categorically, is or is not, as if it were black or white. The momentary pockets of emancipation that were identified in the data, show us that emancipation is not an ideal that we should strive towards as a complete accomplishment but, rather, is built up by striving towards moments in which emancipation takes place, where emancipation becomes a disruption of dominant logics. Furthermore, this reconfiguration implies that emancipation and control do not stand across from each other as complete opposites but rather, exist as two weights on a balance. According to Spaaij et al. (2016), working towards emancipation can therefore imply both adding weight on the emancipatory side - by working towards those moments of emancipation - as well as removing weight from the controlling side by defying it. Accordingly, these pockets of emancipation could be seen as moments wherein practitioners continuously try to tip the balance towards the transformative potential of community sport.

Second, the possible reconfiguration of the concept of emancipation does not imply that research should stop looking for ways to support these pockets of emancipation. The data only shows us traces of these moments, which implies that research is needed that combines critical inquiry with the theoretical development of this issue. In the first place, such a research agenda might provide grounds to propose theory based strategies of resistance (Garret 2013), which seems important given the 
fact that 'community sport in particular lack[s] any ideological critique' (Crabbe 2007, 39) to become armed against this dominant tendency. Moreover, by installing this research agenda, practices may further recognise the hegemony of social control, as Butler et al. (2016) argue that recognising this dominance might lead practitioners to contemplate strategies of resistance. Furthermore, making the developed strategies of resistance visible in academic debates is pivotal to the practice of community sport, as keeping these strategies 'under the radar' might risk practitioners internalising their resistance as personal displeasure rather than seeing it as a structural and political problem and a matter for collective action (Aronson and Smith 2014). Likewise, the traces of emancipation we found in the perspectives of Flemish practitioners might so be further developed.

\section{Funding statements}

This research project is subsidized by the Flemish Government Agency for Innovation and Entrepreneurship.

\section{References}

Aronson J., K, Smith. 2011. Identity Work and Critical Social Service Management: Balancing on a Tightrope? British Journal of Social Work 41: 432-448.

Belton, B. 2010. Radical youth work. Lyme Regis: Russell House.

Black, D. R. 2017. The Challenges of Articulating 'Top Down' and 'Bottom Up' Development through Sport. Third World Thematics: A TWQ Journal 2 (1): 7-22. Blackshaw, T. and T. Crabbe. 2004. New Perspectives on Sport and 'Deviance'. Consumption, Performativity and Social Control. New York: Routledge.

Bramham, P., K. Hylton, K., D Jackson, and M. Nesti. 2001. Introduction. In Sport Development: Policy, Process and Practice, edited by Hylton, K., P. Bramham, F. Jackon and M. Nesti, 1-6. London: Routledge.

Brown, K. 2017. Vulnerability and Young People. Care and Control in Policy and Practice. Bristol: Policy Press. 
Butler, J., Z., Gambetti, and L. Sabsai. 2016. Vulnerability in Resistance. London: Duke University Press.

Community Sport Brugge. 2016. Evaluatieverslag buurtsport Bruges [Evaluation report Community sport Bruges]. Bruges: Community Sport Bruges.

Community Sport Kortrijk. 2016. Actieplan buurtsport Kortrijk [Action Plan Community Sport Kortrijk]. Kortrijk: vzw AJKO.

Crabbe, T. 2007. Reaching the 'Heard to Reach': Engagement, Relationship Building and Social Control in Sport Based Social Inclusion Work. International Journal of Sport Management and Marketing 2 (1/2): 27-40.

Crabbe, T. 2009. Getting to Know You: Using Sport to Engage and Build Relationships with Socially Marginalized Youth. In Sport and International Development, edited by R. Levermore and A. Beacom, 176-198. England: Palgrave MacMillan.

Crawford, A. 2009. Criminalizing Sociability through Anti-Social Behaviour Legislation: Dispersal Powers, Young People and the Police. Youth Justice 9 (1): 5-26.

Darnell, S. C. 2010. Power, Politics and Sport for Development and Peace: Investigating the Utility of Sport for International Development. Sociology of Sport Journal 27 (1): 54-75.

Darnell, S. C. and Dao, M. (2017). Considering Sport for Development and Peace through the Capabilities Approach. Third World Thematics: A TWQ Journal. 2 (1): 23-36.

DiCicco-Bloom, B., and B. F. Crabtree. 2006. The Qualitative Research Interview, Medical Education 40: 314-321.

Ekholm, D. 2016. Sport as a Means of Responding to Social Problems. PhD diss., Linköping University.

Ekholm, D. 2017. Sport-based Risk Management: Shaping Motivated, Responsible and Self-Governing Citizen Subjects. European Journal for Sport and Society 14 (1): 60-78.

Flemish Government. 2016a. Gemeentelijke profielschets Bruges [Municipal Profile]. Vlaanderen: Studiedienst Vlaamse Regering.

Flemish Government. 2016b. Gemeentelijke profielschets Kortrijk [Municipal Profile]. Vlaanderen: Studiedienst Vlaamse Regering.

Flemish Government. 2016c. Gemeentelijke profielschets Ronse [Municipal Profile]. Vlaanderen: Studiedienst Vlaamse Regering.

Freire, P. 1998. Pedagogy of Freedom. Ethics, Democracy, and Civic Courage. Boulder, CO: Rowman \& Littlefield. 
Freire, P. 2005. Pedagogy of the Oppressed. London: Continuum.

Garrett, P. M. 2013. Social Work and Social Theory. Making Connections. Bristol: The Policy Press.

Harvey, D. 2005. A brief history of neoliberalism. New York: Oxford University Press.

Harrison, M., and T. Sanders. 2014. Social Policies and Social Control. New Perspectives on the 'Not-so-big-society'. Bristol: Policy Press.

Hartmann, D., and C. Kwauk. 2011. Sport and Development: An Overview, Critique, and Reconstruction. Journal of Sport and Social Issues 35(3): 284-305.

Haudenhuyse, R., M. Theeboom, and F. Coalter. 2012. The Potential of Sports-based Social Interventions for Vulnerable Youth: Implications for Sport Coaches and Youth Workers. Journal of Youth Studies 15(4): 437-454.

Hsieh, H. F., and S. A. Shannon. 2005. Three Approaches to Qualitative Content Analysis. Qualitative Health Research 15 (9): 1277-1288.

Hylton, K., and M. Totten. 2008. Community Sport Development. In Sports Development: Policy, Process and Practice, edited by K. Hylton, and P. Bramham, 17-77. London: Routledge.

Kelly, L. 2010. Social Inclusion through Sports-based Interventions? Critical Social Policy 31 (1): 126-150.

Kelly, L. 2012. Sports-based Interventions and the Local Governance of Youth Crime and Antisocial Behavior. Journal of Sport and Social Issues 37 (3): 261-283.

Levitas, R. et al., (2007) The Multi-dimensional Analysis of Social Exclusion. Project Report. University of Bristol, Bristol.

Luguetti, C., K. L. Oliver., L. E. P. B. T. Dantas., and K. David. 'The Life of Crime Does Not Pay; Stop and Think!': The Process of Co-Constructing a Prototype Pedagogical Model of Sport for Working with Youth from Socially Vulnerable Backgrounds. Physical Education and Sport Pedagogy 22 (4): 239-348.

Mortelmans, D. 2007. Handboek kwalitatieve onderzoeksmethoden. Leuven: Acco.

Municipality Ronse. 2008-2013. Sportbeleidsplan 2008-2013 Ronse [Sport Policy Plan 2008-2013 Ronse]. Ronse: Stad Ronse.

Nussbaum, M. 2011. Creating Capabilities: The Human Development Approach. Cambridge: Harvard University Press.

Nols, Z., R. Haudenhuyse, R. Spaaij, and M. Theeboom. 2018. Social Change through an Urban Sport for Development Initiative? Investigating Critical Pedagogy through the Voices of Young People. Sport, Education and Society 
Piessens, A. 2008. De grammatica van het welzijnswerk. Ghent: Academia Press.

Province West-Flanders. 2014. Kansarmoedeatlas West-Vlaanderen, [Poverty atlas West-Flanders]. Province West-Flanders, accessed at: https://webshop.westvlaanderen.be (26 July 2017).

Rose, N. 2000. Government and Control. British Journal of Criminology 40, 321-339.

Sen, A. 1999. Development as Freedom. Oxford: University Press.

Skinner, J., D. Zakus, and J. Cowell. 2008. Development through Sport: Building Social Capital in Disadvantaged Communities. Sport Management Review 11(3): 253275.

Spaaij, R. 2009 Sport as a Vehicle for Social Mobility and Regulation of Disadvantaged Urban Youth, International Review for the Sociology of Sport 44 (2/3): 247-264.

Spaaij, R. 2011. Sport and Social Mobility: Crossing Boundaries. New York: Routledge.

Spaaij, R. 2013. Sport, Social Cohesion and Community Building: Managing the Nexus. In Managing Social Issues: A Public Values Perspective, edited by P. Leisink, 107-125.Cheltenham: Edward Elgar.

Spaaij, R., S. Oxford, and Jeanes R. Transforming through Sport? Critical Pedagogy and Sport for Development. Sport, Education and Society 21 (4): 570-587.

Suzuki, N. 2017. A Capability Approach to Understand Sport for Social Inclusion: Agency, Structure and Organisation. Social Inclusion 5 (2): 150-158.

Svensson, P. G. and J. Levine, 2017. Rethinking Sport for Development and Peace: The Capability Approach. Sport in Society. 20 (7): 905-923.

Theeboom, M., R. Haudenhuyse, and P. De Knop. 2010. Community Sports Development for Socially Deprived Groups: A Wider Role for the Commercial Sports Sector? A Look at The Flemish Situation, Sport in Society 13 (9): 13921410.

Thomas, R., A, Davies. 2005. Theorizing the Micro-politics of Resistance: New Public Management and Managerial Identities in the UK Public Services. Organization Studies 26 (5): 683-706.

Wacquant, L. 2012. Three steps to a historical anthropology of actually existing neoliberalism. Social Anthropology 20 (1): 66-79.

Westbrook, L. (1994). Qualitative Research Methods: A Review of Major Stages, Data Analysis Techniques, and Quality Controls. Information Science Research, 16 (3), 241-254. 
Wright, P. M., J. M. Jacobs, J. D. Ressler, and J. Jinhong. 2016. Teaching for Transformative Educational Experience in a Sport for Development Program. Sport, Education and Society 21 (4): 531-548. 